\title{
EDUCAÇÃO PARA O RISCO: regulando a docência em ciências na era da insegurança
}

\author{
Samuel Molina Schnorr \\ Universidade Federal do Rio de Janeiro - UFRJ, Brasil \\ Thiago Ranniery \\ Universidade Federal do Rio de Janeiro - UFRJ, Brasil
}

\begin{abstract}
Resumo
Neste artigo, assumimos uma postura que responde ética e politicamente à rapidez da diferenciação, da volatilidade e da mobilidade do risco nas políticas curriculares para educação científica. Tendo como intercessor analítico um arquivo composto de diferentes documentos curriculares de distintos países das últimas duas décadas, atentamos para os múltiplos modos de regulação subjetiva traçadas entre formação/atuação de professores de ciências, agenciamento global do risco e neoliberalismo. Analisamos como o agenciamento global do risco congrega práticas complexas e múltiplas de conjuração espaço-temporal de discursos e afetos por meio das quais formas de ser professores de ciências são negociadas globalmente. Abordamos, também, a produção dessas formas particulares de ser professor de ciências, examinando como incorporam a docência em um arranjo mais amplo do ethos neoliberal e fazem dela um agente mediador de valores como individualismo, autorregulação e empresariamento de si. Assim, buscamos demonstrar como o risco, alterando e modulando currículos de ciências globalmente, opera constituindo uma instável economia política moral e subjetiva da docência na era da insegurança.
\end{abstract}

Palavras-chave: Sociedade do risco; Educação científica; Formação/atuação de professores; Políticas curriculares.

\begin{abstract}
In this article, we take a stance that responds ethically and politically to the rapidity of differentiation, volatility, and mobility of risk in curriculum policies for science education. Having as analytical intercessor an archive composed of different curricular documents from different countries of the last two decades, we pay attention to the multiple modes of subjective regulation traced between science teacher training/practice, global risk management, and neoliberalism. We analyze how the global risk agency brings together complex and multiple practices of spatiotemporal conjuration of discourses, and affections through which ways of being science teachers are globally negotiated. We also approach the production of these particular ways of being a science teacher, examining how they incorporate teaching in a broader arrangement of the neoliberal ethos e makes it a mediating agent of values such as individualism, self-regulation, and self-entrepreneurship. Thus, we seek to demonstrate how risk, changing and modulating science curricula globally, operates constituting an unstable moral and subjective political economy of teaching in the era of insecurity.
\end{abstract}

Keywords: Risk society; Science education; Teacher training/practice; Curriculum policies. 
A escola que acolhe as juventudes precisa se estruturar de maneira a: (...); proporcionar uma cultura favorável ao desenvolvimento de atitudes, capacidades e valores que promovam o empreendedorismo (criatividade, inovação, organização, planejamento, responsabilidade, liderança, colaboração, visão de futuro, assunção de riscos, resiliência e curiosidade científica, entre outros), entendido como competência essencial ao desenvolvimento pessoal, à cidadania ativa, à inclusão social e à empregabilidade (BRASIL, 2018, p. 466).

Os professores podem ajudar os alunos a compreender que a resolução de problemas de qualquer tipo geralmente requer um gasto considerável de tempo e energia e muita perseverança. Os professores também podem incentivar os alunos a investigar, raciocinar e explorar soluções alternativas e assumir os riscos necessários para se tornarem solucionadores de problemas bem-sucedidos (ONTÁRIO, 2008, p. 7) ${ }^{1}$.

Os alunos às vezes veem os danos sociais do fracasso tecnológico como inaceitáveis. Por outro lado, alguns acreditam que se o risco é pessoal e voluntário, então faz parte da vida e não deve ser preocupação dos outros (ou da sociedade). Ajudar os alunos a desenvolver uma compreensão dos riscos e benefícios nas áreas de saúde, perigos naturais - e ciência e tecnologia em geral - representa um desafio para os professores do ensino médio (ESTADOS UNIDOS, 2013, p. 167).

Neste artigo, nós nos debruçaremos sobre os múltiplos modos de regulação subjetiva traçadas entre formação/atuação de professores de ciências, agenciamento global do risco e neoliberalismo, tendo como intercessor analítico um arquivo composto de diferentes documentos curriculares de distintos países. O trabalho com textos políticos circulantes em variadas esferas nacionais, cruzando-os e contrastando-os é um caminho que busca, de algum modo, levar a sério a afirmação de Michel Foucault (2012) sobre como "todo sistema de educação é uma maneira política de manter ou de modificar a apropriação dos discursos, com os saberes e os poderes que eles trazem consigo" (p. 45). Nosso enquadramento teórico se moverá, deste modo, através da inflexão pós-estrutural no pensamento curricular brasileiro, inspiradora, nestas páginas, por nos permitir "contesta[r] modos de entender o mundo enquanto contesta a si mesma" (MACEDO; RANNIERY, 2018, p. 755). Foi essa inflexão que levou, recentemente, por exemplo, Clívio Pimentel Júnior, Rosanne Dias e Maria Inez Carvalho (2019) a sugerirem que a histórica hegemonização da Natureza da Ciência nos currículos de ciências sobredetermina cultural, política e ontologicamente, dentre outras coisas, formas de ser professor desta disciplina escolar. Pimentel Júnior (2017, p. 88) argumenta ainda que tal figuração hegemônica projeta um perfil de professor de ciências tendo como seu espelho negativo "aquilo que não pode ser inextirpável da educação: o risco da/na experiência formativa".

Todavia, de modo suplementar, vamos sugerir, nas páginas que se seguem, que o risco, nos documentos curriculares mobilizados por nós, se torna um dispositivo de regulação da docência, "cifra de uma matéria 'dividual' a ser controlada" (DELEUZE, 1992, p. 225). 
Suplementar porque, longe da oposição ao argumento do autor, seria preciso reconhecer que Pimentel Júnior (2017) recorre à Gert Biesta (2016, p. 1), para quem o risco é constitutivo da educação "porque os estudantes não devem ser vistos como objetos a serem moldados e disciplinados, mas como sujeitos de ação e responsabilidade". De modo similar, Merilin Baldan e Érika Cunha (2020), ao comentarem a Resolução CNE/CP no 2/2019 que instituiu as Diretrizes Curriculares Nacionais para a Formação Inicial de Professores para a Educação Básica no Brasil, argumentam em torno de uma agenda global, segunda a qual, trata-se de "inventar um novo ser professor não mais sensível às relações e aos contextos e suas realidades complexas" (p. 18). Percorremos, aqui, por outra via, uma política de globalização do risco que, ao invés de obliterá-lo, reconhece e incorpora o risco aos currículos de ciências, localizando-o como um princípio da vida social e com potencial formador para a atuação de professores de ciências, que já não devem mais disciplinar ou moldar estudantes, mas antes devem chamá-los à ação e à responsabilidade. E, assim, acompanhamos um agenciamento global que apela, agora, à complexidade da realidade e aos contextos locais para, seguindo o argumento de Merilin Baldan e Érika Cunha (2020), conectar a educação ao futuro pela transformação da subjetividade docente pelo risco.

Em nosso movimento, o risco se torna um catalisador discursivo, afetivo e material, através do qual se pode percorrer as linhas de subjetivação da docência em ciências no interior das formas contemporâneas do capitalismo, cujo modo de funcionamento "consiste na articulação de fluxos econômicos, tecnológicos e sociais com a produção da subjetividade de tal maneira que a economia política se mostre idêntica à "economia subjetiva", (LAZZARATO, 2011, p. 14). Articulada de forma coextensiva a modulação subjetiva do risco tanto por meio do cálculo e da antecipação quanto por meio da incerteza e da insegurança, a docência em ciências é chamada à tarefa de recriação contínua de sujeitos que, se está em consonância com o alargamento das funções sociais da escola pelo neoliberalismo (LOCKMAN; MACHADO, 2018; CHAGAS; LOCKAMN, 2021), ressoa uma sociedade escandalizada com a iminente catástrofe do próprio fim. Para explorar tal argumento, na sessão seguinte, nós apresentamos os percursos teóricos-metodológicos que nos inspiraram a tratar o risco como um agenciamento global e os modos de leitura que acionaremos para enfrentar como tais textos curriculares estão implicados em políticas de subjetivação. Em seguida, nós vamos recensear as marcas subjetivas que são combinadas e recombinadas para agenciar a docência em ciências traçadas nos documentos - o construtor de capacidades, o gestor de habilidades e o desenvolvedor profissional - e, no passo, esperamos traçar como políticas neoliberais de subjetivação docente não são entidades monolíticas.

\section{Por um dentro de um agenciamento global}

Abrimos este artigo, propositalmente, com uma sobreposição de variadas citações retiradas de diferentes documentos curriculares nacionais das últimas duas décadas. São enxertos que enredam crenças ontológicas, conceitos e compromissos sobre educação, ciência, ensino de ciências, tecnologia, sociedade, aprendizagem, estudantes, professores, 
subjetividade, cruzando diferentes arenas públicas e privadas. Em conjunto, esses trechos ensejam aquilo que desejamos colocar em discussão: os ângulos difratados da emergência do risco como um dispositivo de regulação da docência. Todos estes enxertos, derivados de uma multiplicidade geográfica de documentos curriculares, trazem à cena o risco nas políticas de currículo de ciências e apontam para múltiplas direções e díspares dimensões daquilo que Stephen Collier e Aihwa Ong (2005), certa vez, chamaram de um agenciamento global. Uma proposição que nos é inspiradora para explorar as tensões inerentes desta globalização do risco atravessando e constituindo a docência em ciências. Nas palavras dos autores, ao explicarem o uso do conceito de agenciamento global: "global implica amplamente abrangente, contínuo e móvel; agenciamento implica em heterogêneo, contingente, instável, parcial e situado" (COLLIER; ONG, 2005, p. 12). Como, então, o risco se tornou um problema educacional global para a formação de professores? Por que ou de que forma a educação científica passou a prestar atenção tão firmemente no risco em diferentes países e quase que simultaneamente? Como o risco faz funcionar a docência em ciências?

Para seguir neste sentido, o escopo da pesquisa que subsidia este texto se centralizou, naquilo que Stephen Ball (1994), uma vez, nomeou de contexto de produção do texto, em torno do qual construímos um arquivo documental de textos de reformas curriculares internacionais (Fig. 1). Nós vamos nos debruçar sobre documentos de treze diferentes países em quatro continentes (Brasil, Chile, Inglaterra, Espanha, Europa, Moçambique, Nova Zelândia, Canadá, Portugal, África do Sul, Reino Unido e Estados Unidos). "Debruçar", aqui, vale indicar, não significa esgotar, de uma vez por todas, tais textos, mas percorrer de forma espasmódica a consistente e extensa proliferação do risco, isto é, "uma série de segmentos descontínuos, cuja função tática não é uniforme nem estável” (FOUCAULT, 1999, p. 111). Próximo ao exercício de leitura topológica sugerido por Elizabeth Macedo (2016), exploramos as marcas de um agenciamento global que vem situando o risco como um tema educacional, ao mesmo tempo, um objeto de ensino e um problema para formação de professores nas políticas curriculares da educação científica. Embora não possamos afirmar que tais textos foram escolhidos aleatoriamente, vale destacar também que não são propriamente textos representativos. Antes, esse arquivo de pesquisa é composto por textos reconhecidos e validados pela literatura acadêmica sobre educação em ciências por evidenciarem práticas pedagógicas e circulação de apropriações teóricas, temáticas e empíricas que passam a dar ao risco um estatuto nos currículos ${ }^{2}$. 
Figura 1. Uma visão geral dos países, o ano de publicação e os currículos selecionados para uma análise sobre o risco na educação científica

\begin{tabular}{|c|c|c|}
\hline Documento & Região/País & $\begin{array}{c}\text { Ano de } \\
\text { Publicação }\end{array}$ \\
\hline The Australian Curriculum & Austrália & 2015 \\
\hline Base Nacional Comum Curricular & Brasil & 2018 \\
\hline Ciencias Naturales - Programa de Estudio & Chile & 2019 \\
\hline National curriculum in England: science programmes of study & Inglaterra & 2014 \\
\hline $\begin{array}{l}\text { Currículo básico de la Educación Primaria y de la Educación } \\
\text { Secundaria Obligatoria. }\end{array}$ & Espanha & 2014 \\
\hline Science Education for Responsible Citizenship & $\begin{array}{c}\text { Comissão } \\
\text { Europeia }\end{array}$ & 2015 \\
\hline Plano Estratégico da Educação 2020-2029 & Moçambique & 2020 \\
\hline The New Zealand Curriculum & Nova Zelândia & 2007 \\
\hline The Ontario Curriculum & Ontário - Canadá & 2008 \\
\hline Orientações e Metas Curriculares & Portugal & 2004 \\
\hline National Curriculum Statements & África do Sul & 2011 \\
\hline $\begin{array}{c}\text { Twenty First Century Science: science today - for scientists of } \\
\text { tomorrow }\end{array}$ & Reino Unido & 2011 \\
\hline Next Generation Science Standards & Estados Unidos & 2013 \\
\hline
\end{tabular}

Nosso interesse incidiu, deste modo, sobre o que esses documentos fazem circular e como se relacionam, o que assumem e fazem funcionar (SEVERIANO, 2016). Este é um modo de ler tais textos que segue a conhecida lição de Rosa Maria Bueno Fischer (2001, p. 205) sobre como fazer pesquisa, neste sentido, é perguntar "por que isso é dito aqui, deste modo, nesta situação, e não em outro tempo e lugar, de forma diferente?". Trata-se de um trabalho sobre e com estes textos, cuja inspiração também é o argumento de Michel Foucault (2012), para quem existe um limiar de reconhecimento onde somente alguns discursos chegam e que uma positividade reforçaria essas práticas dentro de um regime que os acolhe e os faz aparecer como verdadeiros. Os enunciados que fazem o risco funcionar em documentos curriculares também engendram através destes textos um conjunto de práticas que implicam em modo heterogêneo de tornar-se e regular-se professor. Nosso exercício analítico segue, deste modo, as imbricações da proliferação do risco com a formação/atuação 
docente em ciências para, ao menos começar, a trazer à tona, na frase de Gísli Pálsson e Paul Rabinow (2005, p. 94), "uma conjuntura histórica, política e econômica específica em que uma questão se torna um problema".

No coração desta analítica, está, assim, aquilo que convencionamos chamar de neoliberalismo, tal como, uma vez, definiu Nikolas Rose (1996): uma racionalidade política que busca governar condutas não por meio de operações de comando e controle, mas por meio da escolha calculada de atores formalmente livres. Em outras palavras, neoliberalismo é um sistema de raciocínio, uma normatividade, do tipo de mercado e, como tal, provou ser altamente expansiva e móvel para diferentes esferas dos laços sociais, algo que Wendy Brown (2015) nomeou através da expressão de economização da vida e inclui, muitas vezes, individualização reflexiva, flexibilidade e ansiedade (EDWARDS, 1998; SAFLATE, 2021). Disso decorre, argumenta Suely Rolnik (2018, p. 33), que a fonte da qual o neoliberalismo "extrai sua força não é apenas econômica, mas também intrínseca e indissociavelmente cultural e subjetiva - para não dizer ontológica". Consideramos, nesta perspectiva, esse gesto teórico-metodológico uma possibilidade para problematizar a relação entre o risco e regulação da docência colocada em operação por tais políticas curriculares em ciências desde do ponto de vista da produção de subjetividades - ou, ao menos, do desejo de instituir um sujeito docente, posto assumirmos, aqui, que "o sujeito não é uma fonte autônoma e transparente de saber - é constituído em redes de práticas sociais que sempre incorporam relações de poder e exclusões" (OKSALA, 2011, p. 13).

Como destaca Vera Portocarrero (2009, p. 144), trata-se de um percurso que "nos possibilita responder à questão quem somos nós no presente e como nos tornamos quem somos, de modo a provocar novas formas de pensar sobre nós mesmos e sobre o mundo". Nós mapeamos, deste modo, as forças que estão modulando as maneiras pelas quais professores de ciências deveriam se pensar como docentes; quais questões, que necessidades e quais ações são necessárias para que respondam à "sociedade do risco", à medida que tal sociedade vai simultaneamente se constituindo como tal. Logo, nosso argumento é que o risco, atravessando e se materializando em diferentes documentos curriculares, não é sobre mercantilizar a docência, mas é um daquelas tecnologias políticas descritas por Ball (2002) para reformar e mudar o que significa ser professor; uma tecnologia que sutilmente reengenharia valores morais, procedimentos e formas substantivas de sociabilidade, de relação do sujeito consigo mesmo e com outros, contribuindo para a constituição de noções particulares de subjetividade e prática docente.

Deste modo, percorrer as linhas de força do risco, circulando globalmente através desses textos curriculares, envolve enfrentar formações sociais e econômicas, uma complexa gama de elementos e processos inter-relacionados, mesmo que aparentemente disparatados, que se reúnem na produção desse agenciamento global. Tal como Deborah Youdell (2015) vem defendendo, ao entendermos esses textos políticos como partes operatórias de um agenciamento global, estamos assumindo que o risco não se esgota nas reformas curriculares, de modo que esses documentos estão situados e conectados dentro de relações mais amplas do agenciamento do risco. Segue, portanto, o porquê a inspiração em Gilles Deleuze (2005) de Collier e Ong (2015) para escreverem em termos de agenciamento global, com a qual 
introduzimos esta sessão, nos soou particularmente produtiva a fim de acompanhar campos de produção de subjetividade docente em torno do risco como mudando por sua própria constituição. O conceito de agenciamento, explorado por Deleuze e Félix Guattari (2017), fornece um intercessor para pensar em como diferentes elementos se emaranham em relações produtivas para formar entidades sociais móveis.

Trata-se, sobretudo, de um convite para percorrer uma matriz transescalar e temporalmente múltipla de níveis, componentes e fluxos que incluem economia, estado, legislação, política, instituições, organizações, formas culturais, discurso, subjetividade e afetos em relações móveis e produtivas, ao invés de elementos estáticos ou independentes. Nas palavras de Deleuze e Guattari (2017):

Um agenciamento em sua multiplicidade trabalha forçosamente, ao mesmo tempo, sobre fluxos semióticos, fluxos materiais e fluxos sociais (independentemente da retomada que pode ser feita dele num corpus teórico ou científico). Não se tem mais uma tripartição entre um campo de realidade, o mundo, um campo de representação, o livro, e um campo de subjetividade, o autor. Mas um agenciamento põe em conexão certas multiplicidades tomadas em cada uma destas ordens [...] (DELEUZE; GUATTARI, 2017, p. 45).

Em resumo, este artigo analisa como o agenciamento global do risco congrega práticas complexas e múltiplas de conjuração espaço-temporal de discursos e afetos por meio das quais formas de ser professores de ciências são negociadas globalmente. Nós mobilizamos afetos como parte do agenciamento global do risco porque concordamos com Lawrence Grossberg (2018) para quem as políticas neoliberais deveriam ser discutidas em termos afetivos, isto é, tendo-se em conta as condições de possibilidade através dos quais as pessoas podem experienciar determinados processos e fenômenos, englobando "uma variedade de formas pelas quais 'sentimos' o mundo na nossa experiência" (GROSSBERG, 2018, p. 11). Afeto é, nas palavras do autor, "uma dimensão essencial ou ingrediente da desordenada experiência humana [...] produto contingente de eventos, contradições e lutas humanas e nãohumanas" (GROSSBERG, 2018, p. 10), variando no espaço-tempo. No que se segue, medo, ansiedade, pânico e incerteza não são, deste modo, um mero pano de fundo do agenciamento global risco, mas afetos ativamente mobilizados e catalisados por fluxos discursivos e materiais, constituindo ritmos e sensações da experiência subjetiva da docência em ciências.

Por extensão, abordaremos como a produção de formas de ser professor de ciências, "é sempre constituída no espaço entre individualidade e sociabilidade, entre consciência e materialidade, entre o cognoscível e o ainda-não-articulado" (GROSSBERG, 2018, p. 91), examinando como tais formas incorporam a docência no arranjo afetivo mais amplo do risco. Realizamos tal exercício porque, como esperamos mostrar, a regulação subjetiva em jogo torna o professor de ciências um agente mediador de valores do ethos neoliberal, mas só o faz à medida em que o constitui subjetivamente como estando sempre e diante de tudo que está em iminência de uma crise ou de uma quebra. A mudança projetada pela e para a educação científica e que professores de ciência deveriam ser capazes de promover ocorre 
não por simples imposição de uma ordem normativa de cima para baixo, mas por meio da circulação de poder em níveis micropolíticos. Ensinar ciências para o risco torna-se um programa de auto-regulação da docência que coloca professores para "trabalhar dentro, pela e em nome da comunidade" (CAMPBELL, 2011, p. 69), da cidadania e da democracia.

Nosso esforço é ainda para evitar que o agenciamento global do risco seja tomado por uma lista de elementos estáticos e separados, organizados para produzir coletivamente uma formação inteira ou completa. A ênfase, por sua vez, está em movimentos e fluxos discursos e afetivos que se transformam, chocam-se, deslocam-se e recompõem-se, co-constituindo-se, pois, "as relações entre eles não são logicamente necessárias, mas apenas contingentemente obrigatórias: um resultado histórico de sua coevolução próxima" (DELANDA, 2006, p. 12). No que se segue, portanto, vale frisar ainda que nos debruçaremos mais sobre as ressonâncias entre os textos levantados, traçando pistas de como estão entrelaçados e colocam em ação uma rede de forças e poderes, mais do que mapeando contrastes entre eles. Neste exercício analítico de percorrer repetições ecoantes que os aproximam, pediremos alguma licença para abdicar, por hora, de traçar as condições locais de emergência de cada um dos textos políticos. Em parte, porque o agenciamento global do risco em muito suspende a distinção global/local, nacional/internacional. Em parte, também, porque seguimos Ball (2014) e desejamos lançar foco sobre os fluxos transnacionais de políticas curriculares que se espraiam globalmente.

Nós utilizamos os textos como compondo uma rede de forças e esperamos, assim, apontar que existem ambivalências, paradoxos e incongruências imanentes ao próprio agenciamento global do risco, antes que propriamente sinalizar como tais incoerências estão contidas em cada texto. Longe, da manifestação de uma mesma essência econômica causal na educação científica, buscamos demonstrar como o risco, alterando e modulando currículos de ciências globalmente, opera constituindo uma instável economia política moral e afetiva da docência na era da insegurança. Nossa questão não é, portanto, definir ou caracterizar o que é uma educação para o risco e como deve ser a formação de professores de ciências neste sentido ou como vem sendo pensada em cada um dos países em cada texto se produziu. A pergunta o que é ?, como bem lembra Deleuze (2004), nunca é boa para acompanhar os dinamismos espaço-temporais de um agenciamento. É o próprio Deleuze (2005, p. 46) que, comentando a obra de Michel Foucault, nos oferece um modo de abordar o agenciamento global do risco menos como uma lei essencial do neoliberalismo e mais como um diagrama em circulação, pois o diagrama é "a exposição das relações de força que constituem o poder". Nos termos de Deleuze (2005, p. 45), "as alianças tecem uma rede flexível e transversal, [...] definem uma prática, um procedimento ou uma estratégia, distintos de toda combinatória, e formam um sistema físico instável, em perpétuo desequilíbrio, em vez de um círculo fechado de troca [...].”.Tal postura é, ao menos de nossa parte, uma resposta ética e política à rapidez da diferenciação, da volatilidade e da mobilidade do risco nas políticas curriculares para educação científica neste nosso tempo das catástrofes. 


\section{A sociedade do risco: desenhando professores de ciências}

Nada é um risco em si mesmo; não há risco na realidade. Por outro lado, tudo pode ser um risco; tudo depende de como se analisa o perigo, se considera o evento (EWALD, 1991, p. 199).

Quando Ulrich Beck (2013) cunhou a noção de sociedade do risco, ainda no final dos anos de $1980^{3}$, para descrever "uma nova forma de capitalismo, uma nova forma de economia, uma nova forma de ordem global, uma nova forma de sociedade e uma nova forma de vida pessoal" (BECK, 1999 p. 2), os cientistas sociais enfrentavam o "choque antropológico nas populações das sociedades industrializadas do Ocidente no que se refere ao desenvolvimento tecnológico" (GUIVANT, 1997, p. 17). A referência explícita de Beck era o acidente de Chernobyl e como havia galvanizado as denúncias de devastação ecológica decorrente da industrialização e as ameaças das armas de destruição em massa. Em toda sua extensão, as armas químicas, biológicas e nucleares aumentavam a sensação de guerra instalada ${ }^{4}$, em especial quando vinculadas aos fundamentalismos de ocasião e ao terrorismo ${ }^{5}$. As evidências e respostas da ciência e as crenças na tecnologia passariam a ser percebidas, pela população em geral e pelos tomadores de decisão, como frágeis e conflituosas. Essas situações levaram a uma desconfiança das instituições e das bases tradicionais que respondiam aos anseios subjetivos e ofereciam uma ideia de futuro seguro e estável (DOUGLAS, 1994). Não seria sem propósito sugerir que derivou daí, como diagnosticaram Deleuze e Guattari (2012, p. 182), "uma nova concepção da segurança como guerra materializada, como insegurança organizada ou catástrofe programada, distribuída, molecularizada"

Havia, àquela altura, nos argumentos de Beck (2013), algo de prospectivo, para não dizer profético, reconhecido, de fato pelo próprio autor, quando afirmou querer, através do epíteto sociedade do risco, "tornar visível o futuro que já se anuncia no presente" (BECK, 2013, p. 11). Mais de três décadas depois da publicação deste livro seminal, parece que, agora, este futuro se tornou um presente total e está mais um diagnóstico de como passamos a encarar os riscos como uma condição indissociável e inerradicável da vida social. Não sem razão, Beck (2013) já sinalizava, ali, que cientistas, órgãos governamentais e agências reguladoras começavam a reconhecer a necessidade de colocar em prática um novo modelo de produção de conhecimento e de tomada de decisões para enfrentar as incertezas de viver em uma sociedade que produz os próprios riscos. Uma virada passa, assim, a exigir da educação a desempenhar um papel na preparação dos futuros cidadãos para essa sociedade. Ou, em outros termos,

Refletir de forma argumentada sobre o sentido de risco e sua relação para chegar a soluções inovadoras e, portanto, a possibilidade de evolução. Discutir a importância de se arriscar e sair da chamada zona de conforto para atingir metas e obter resultados criativos e inovadores (ESPANHA, 2014, p. 494). 
Mais do que um exemplo, o trecho do currículo nacional espanhol sintetiza como, em termos gerais, os projetos curriculares de ciências que percorremos orientados pelos riscos destacam mudanças em direção à reflexividade, individualização e espírito empresarial. Abordado de diferentes modos, o risco ganha destaque por sua natureza probabilística, exigência de trabalho interdisciplinar e pela aproximação de conceitos e questões científicas aos contextos que são relevantes para a vida dos alunos. Por efeito, a educação científica é convocada, nesses diferentes textos, a ajudar no enfrentamento dos riscos sociais atuais e suas incertezas, como as mudanças climáticas, a segurança alimentar e o apelo por cidades sustentáveis. À medida em que vivenciamos e enfrentamos esses riscos, a capacidade de resolver esses problemas e achar soluções "criativas e inovadoras" por conta própria e com diferentes conhecimentos é requisitada. Isso implica em exigir dos alunos e professores habilidades de lidar com risco em uma posição de enfrentamento: "Identificar áreas-chave de atuação e ações que podem ser levadas à cabo com vista a diminuir a gravidade dos impactos através de ações de adaptação e de redução dos riscos climáticos" (MOÇAMBIQUE, 2020, p. 33).

Não muito diferente do que Macedo (2016; 2017) vem apontando para a Base Nacional Comum Curricular (BRASIL, 2018) no Brasil e as relações com as teorizações curriculares, essas histórias discursivas dos documentos curriculares em diferentes países girando em torno dos riscos, sobretudo dos fatores que aumentam ou reduzem um determinado risco, são articuladas também, ainda que não exclusivamente, pela literatura acadêmica da pesquisa em educação em ciências, ao menos internacionalmente. De fato, não somente a discussão recente sobre o currículo escolar de ciências tem se centrado na ideia de alfabetização científica como objetivo curricular (MILLAR, 2006), mas vem explicitamente defendendo desenvolver um modelo de currículo de ciências adequado às necessidades de uma gama mais ampla de alunos e uma compreensão do que os alunos precisarão como cidadãos de uma sociedade caracterizada amplamente pela ciência e tecnologia (LEVINSON et al., 2011). Abundam, de fato, exemplos desta necessária e sonhada mudança de projeto para a educação científica orientada ao e pelo risco:

A alfabetização científica nos ajuda a interpretar e compreender nosso mundo, a gerenciar riscos e colocar a incerteza em perspectiva, a orientar o desenvolvimento tecnológico e a inovação e a prever e planejar o futuro. Melhora as perspectivas de emprego, a consciência cultural e a nossa capacidade de agir como cidadãos bem informados e solidários com os cidadãos de todo o mundo (COMISSÃO EUROPEIA, 2015, p. 16).

Em eco ao documento curricular da Comissão Europeia (2015), Edgar Jenkins (2000) já apelava, por exemplo, vinte anos antes, para que a educação científica passasse a incorporar o risco como um tema de ensino de forma que os cidadãos possam estar mais bem preparados para a tomada de decisões diante incertezas. Stein Dankert Kolst $\varnothing$ (2006) afirma, por sua vez, que os estudantes precisam constantemente avaliar riscos em suas atividades rotineiras e a ciência pode oferecer um suporte para essa avaliação. Kolst $\emptyset$ (2006) segue ainda lamentando 
que as ciências envolvidas com os riscos, especialmente a epidemiologia e a medicina não são incluídas, tradicionalmente, no currículo de ciências da escola, que tem se centrado na física, química e biologia, em grande parte por razões históricas da conjunção disciplinar e da pedagogização do conhecimento científico ${ }^{6}$. Esse requerimento, sugere Clare Christensen (2009), depende de os estudantes alfabetizados cientificamente terem conhecimento, objetividade e habilidades que lhes permitiriam interpretar informações relacionadas aos riscos vivenciados no seu contexto diário. O sujeito a ser formado pela escola, neste sentido, é aquele que faz perguntas, busca respostas, estuda as consequências e toma decisões sobre o risco com base nas informações disponíveis e no conhecimento científico, inovando nas ações e posições pessoais.

A consideração cuidadosa de vários pontos de vista, bem como a evidência científica dos custos e riscos ambientais, permitirá aos alunos não apenas procurar maneiras pelas quais as pessoas podem chegar a um acordo sobre como minimizar os impactos negativos de suas ações, mas também para fazer decisões mais informadas sobre escolhas pessoais (ONTÁRIO, 2008, p. 84)

Há, nesta profusão, diferentes dimensões discursivas e afetivas a serem exploradas. O que nos interessa, por hora, é destacar que tal rotação subjetiva endereçada aos estudantes tal como no enxerto do documento canadense acima - têm reverberações na produção da docência em ciências e do que ela deve ser e incorporar em termos de valores morais e economia subjetiva. Isso porque, de acordo com Beck (2013, p. 87), a emergência de nossa 'sociedade de risco' ocidental foi acompanhada por "uma onda social de individualização", na qual "a modernização reflexiva dissolve os parâmetros tradicionais da sociedade industrial". Dito de outro modo, quando indivíduos enfrentam as ansiedades do neoliberalismo e estão envolvidos com a incerteza global, a subjetividade deveria introjetar a responsabilidade pessoal pela escolha e planejamento da vida, "assumindo a causa da desestabilização como uma suposta deficiência de si mesma" (ROLNIK, 2018, p. 71). Ainda que seja sempre experienciada no presente, esta ansiedade é sempre "uma futuridade" (GROSSBERG, 2018, p. 99) que alimenta os discursos de que professores devem mudar a si mesmos e o que e como ensinam. Isabell Lorey (2014) explicita a extensão desta carga individualizante pelo aumento de um receio instalado no coração da produção da subjetividade. Estaríamos, em seus termos, frente a um novo dispositivo do poder: "um governo que produz a insegurança como preocupação central do sujeito" (LOREY, 2014, p. 8).

Não é de se estranhar, portanto, que a curricularização do risco implicaria, nessas condições, em demandas para rever o modo de apresentarmos a ciência como disciplina do currículo escolar e se apresenta, sobretudo, como uma nova exigência para os professores, aquela a partir da qual eles devem fornecer aos alunos conhecimentos e habilidades que possam ser aplicados a qualquer decisão de risco (SCHENK et al. 2019). Nessa proposição, os docentes precisam estar dispostos e serem capazes de incorporar a educação sobre o risco em suas práticas, pois: 
A ciência é uma disciplina em que o pensamento criativo e às vezes arriscado é importante. Muitas vezes, novas ideias e teorias são o resultado de saltos criativos. Para que os alunos entendam esse aspecto da ciência e estejam dispostos a expressar ideias criativas, todos os membros da comunidade de aprendizagem devem apoiar e respeitar a diversidade de experiências, ideias, pensamentos e expressões. Os professores precisam trabalhar com os alunos para desenvolver um ambiente no qual eles se sintam seguros para expressar ideias (ESTADOS UNIDOS, 2013, p. 46).

Ambivalência? Ambiguidade? Ubiquidade? Talvez, sim. Talvez, não. De fato, embora o termo risco seja amplamente utilizado, não há uma definição propriamente consensual. Tudo e qualquer coisa pode ser um risco e tal flutuação é a marca constitutiva de transformar a incerteza em condição de produção subjetiva ou, nos termos do Next Generation Science Standards (ESTADOS UNIDOS, 2013), oferecer um cenário seguro para viver a incerteza. Reconhecer esta inconsistência não tem a ver com apontar falta de precisão conceitual dos textos curriculares em caracterizar o que é arriscado na sociedade e/ou na ciência para professores ensinarem. Antes, é um modo de operação dos diferentes movimentos produtivos deste agenciamento global, de tal maneira que o risco não é um simples aspecto das políticas curriculares em ciências, mas, ao invés disso, o risco interage produtivamente com uma gama de componentes discursivos da educação em ciências através dos documentos curriculares. Neste movimento, autodescoberta e reflexão tornam-se processos subjetivos divulgados como primários na tarefa do professor projetar os estudantes de ciência, pois os riscos produzem, no mesmo movimento, descontinuidades afetivas (ansiedade, receio, insegurança) por meio da incitação às decisões ambíguas em cenários constitutivamente inseguros.

É fundamental que os alunos compreendam que há benefícios para a humanidade resultantes do desenvolvimento científico e tecnológico que, simultaneamente, colocam em risco pessoas e ambiente. Os alunos devem ter a oportunidade para refletir sobre as implicações ambientais, sociais e/ou emocionais de certos acontecimentos (PORTUGAL, 2004, p. 32).

Em meio a discursos de flexibilidade, reflexividade e individualização, a formação da subjetividade docente deveria construir e assumir a responsabilidade pela "formalização da sociedade com base no modelo empresa" (FOUCAULT, 2010, p. 222) com suas características de iniciativa pessoal, mas também de assunção e avaliação de riscos, bem como auto-regulação diante deles. Por efeito, no caso dos professores de ciências, a docência deveria se concentrar, agora, menos na capacidade de ensinar o conteúdo das ciências e mais na capacidade dos estudantes de tomarem tais decisões por meio do conhecimento científico:

Compreender o papel e a natureza da evidência e do raciocínio científico ao gerenciar o risco por meio de modelagem científica e tecnológica. Entender como as decisões do 'deveria' e do 'poderia' na modelagem científica e tecnológica 
dependem da compreensão de como as evidências podem mudar de valor em diferentes contextos e como diferentes ferramentas são usadas para determinar e mitigar riscos (NOVA ZELÂNDIA, 2007, p. 59).

Ao comentar as reformas curriculares na Austrália, Terri Seddon (1999) documentou como elas dependem da fantasia de converter o professor em construtor de capacidades. Nosso percurso pelos documentos fornece evidências para sinalizar, mesmo que preliminarmente, a emergência de uma problemática em torno da docência em ciências, que é, neste enlace, projetada como uma construtora de capacidades de decisão individual diante dos riscos. Por meio dos ecos do empresariamento de si (AMBROZÍO, 2018), ser professor de ciências torna-se "capacitar" o indivíduo como um tomador de escolhas auto-responsável, vinculado às ansiedades da tomada de decisões que deveriam compeli-lo a desejos de desenvolvimento pessoal. Esta projeção combina, entretanto, simultaneamente, o gestor de habilidades e de desenvolvedor organizacional com marcas vastamente conhecidas da docência. Essas marcas são aquelas que evocam a auto-regulação do poder pastoral, tal qual nomeado por Foucault (2008) e tomado por Thomas Popkewitz e Marie Brennan (1998) para analisar práticas de auto-policiamento nas quais professores tornam a subjetividade objeto do próprio olhar crítico de mediação e controle.

Desta forma, se o risco não deixa de submergir a docência para incorporar o “individualismo possessivo" (COLLIER; ONG, 2005), é simultaneamente orientado pela gramática da libertação e da salvação. No mesmo gesto, entretanto, o risco recoloca essas marcas da docência em ciências no interior das formas neoliberais contemporâneas através da "fusão progressiva dos repertórios de mercado com as linguagens do eu" (ILLOUZ, 2001, p. 54). Neste enlace, os riscos mobilizam, ao mesmo tempo, afetos tão ameaçadores quanto excitantes. Por um lado, são promovidos como uma oportunidade holística, produtiva e capacitadora para facilitar a aprendizagem em ciências dos estudantes de forma que respondam a sociedade em que vivemos. Os professores são, neste sentido, incentivados a considerá-lo como uma oportunidade para educar cientificamente a fim de desenvolver uma maior reflexividade ao ponto que o documento da Comissão Europeia (2015) passa a afirmar que avaliar e comparar os riscos e benefícios são considerados fundamentais para a tomada de decisão e a participação democrática na sociedade.

O sucesso no século 21 depende da aquisição de competências essenciais, e não simplesmente do aprendizado de fatos. Ser capaz de colaborar, ouvir as ideias dos outros, pensar criticamente, ser criativo e ter iniciativa, resolver problemas e avaliar riscos e tomar decisões e gerir emoções de forma construtiva são interdependentes. Eles são considerados essenciais para o sucesso na vida adulta e a base para a aprendizagem ao longo da vida. Contribuem também para uma cidadania ativa a nível local, nacional e global (COMISSÃO EUROPEIA, 2015, p. 20).

No entanto, a possibilidade ilimitada do risco como recurso com potencial pedagógico coexiste com o seu desastre potencial pelo qual os indivíduos devem assumir 
responsabilidade pessoal. Os princípios gêmeos de autorregulação e capital humano, que constroem a vida como um projeto de recursos humanos individualizados sem fim, encontram-se com princípios de promoção de valores morais. Ao explorar a aliança entre o neoliberalismo e a tradicionalidade cristã, Brown $(2019$, p. 48) sugere que esse encontro "salvou [...] o sujeito [...] das forças em desintegração da modernidade tardia" (BROWN, 2019, p. 48) e, não seria sem propósito afirmar, que também projeta a fantasia de salvá-lo da sociedade do risco. O chamado para professores se pensarem como formando estudantes para responderem a sociedade que vivemos também é um convite para uma maior flexibilidade a fim garantir a sobrevivência individual. Entretanto, os professores não devem mais, ao menos não exaustivamente, promover conversão, reforma e disciplinamento. São figurados como um gestor dos riscos que atravessam a sociedade, os quais, para retornar ao argumento de Beck (2013), só começaram a ganhar visibilidade a partir da abertura, nunca antes concedida na história das sociedades, à mecânica dos interesses libertados de vínculos sociais. Para escrever com os termos de Brown (2019, p. 48), trata-se de uma aliança, cujo "o resgate [...] do indivíduo [...] no momento exato de sua aparente extinção" cabe aos professores e aos professores de ciências, em particular. Estes últimos são aqueles que se constituem pela tarefa de fortalecer o indivíduo pela ciência quando o cenário social é vastamente corroído por riscos.

Explorar o risco como veículo pedagógico afirma, portanto, menos o triunfo final dos professores de ciências, mas insere a subjetividade docente em um agenciamento, cujas linhas de força passam pelas atuais práticas de trabalho pós-fordistas para que os professores tornem seus alunos "aprendizes ativos e sujeitos autorregulados" (GARRICK; USHER, 2000, p. 12) a medida que seus modos de subjetivação "funciona[m] através da regulação, infiltrando-se no próprio interior da experiência dos sujeitos" (GARRICK; USHER, 2000, p. 12). No mesmo passo, entretanto, esse movimento trabalha e exige uma ocupação simultânea com a figura símbolo da docência voltada para o desenvolvimento de uma prática de ensino que tenha um objetivo ou habilidade de aprendizagem como seu fim. Esta descontinuidade sinaliza para como o agenciamento global do risco se move regulando a docência em ciências, às vezes funcionando de novas maneiras, mantendo velhas formas, às vezes performando velhas funções dentro de novas formas. Logo, empreendedorismo neoliberal não está remodelando apenas o trabalho docente no sentido formal, mas a própria esfera intersubjetiva da experiência de ensinar de ciências. Como tal, a noção de uma subjetividade neoliberal universal, monolítica ou inevitável que simplesmente visa construir um "sistema perfeito de prevenção" (CASTEL, 1991, p. 293) parece inadequada. Como Deleuze (1992, p. 213) já havia notado, "no capitalismo só existe uma coisa universal, o mercado [...] ele não é universalizante, homogeneizante, é uma fantástica fabricação de riqueza e miséria".

Por mais que o movimento pareça invariavelmente seguir em direção aquilo que Alain Erenbherg (2008) chamou de cultura da performance, viver na sociedade do risco e atuar nela politicamente implicaria práticas consideradas calculáveis que só o são em cenários considerados complexos, impossíveis de serem simplificados a priori. Entre os textos, esta impossibilidade é subitamente confessada, mesmo que a contrapelo. 
Atualmente, muitos dos dilemas políticos e morais que a sociedade enfrenta são colocados pelo avanço da ciência e da tecnologia e requerem uma solução que, embora enraizada na ciência e tecnologia, envolve uma combinação complexa, que passa por uma avaliação de risco e incerteza, uma consideração dos benefícios econômicos e valores, e alguma compreensão dos pontos fortes e limites da ciência. O debate atual sobre como o desafio do aquecimento global deve ser abordado é um exemplo (COMISSÃO EUROPEIA, 2015, p. 22).

Quando a vida é governada como um negócio, os professores de ciências tornam-se mediadores de ansiedade, desalento e insegurança, educadores de um "projeto de sustentação, mas de uma fantasia impraticável" (BERLANT, 2011, p. 188). Novamente, nos termos de Beck,

São os próprios especialistas que sabem que o risco não é uma grandeza mensurável. O que significa então a 'realidade' do risco? A realidade do risco reside no seu caráter duvidoso, discutível. Riscos não possuem uma existência abstrata por si só. Eles se tornam reais nas avaliações contraditórias de grupos e populações. A ideia de um critério objetivo, segundo o qual se possa medir o grau de um risco, desconsidera que somente após uma determinada percepção e avaliação, riscos são considerados como urgentes, perigosos e reais ou como desprezíveis e irreais (BECK, 1999, p. 36)

Trata-se de uma espécie de jogo, através do qual, o risco converte a insegurança como constitutiva de quaisquer contextos, ou seja, o risco é tornado suporte pretensamente universal de um modo de produção subjetiva que "não presta mais que uma garantia mínima e ameaça pela tática da incerteza" (LOREY, 2012, p. 14). Neste sentido, como Beck (1999) sinalizava, os riscos são considerados, antes de tudo, a antecipação da catástrofe, não possuem concretude espaço-temporal ou social, são futuros acontecimentos, cujo prenúncio orienta nossas perspectivas e atitudes, configurando sua força política. Portanto, "somente pela presentificação, pela encenação dos riscos globais, o futuro das catástrofes se transforma em presente, normalmente com o objetivo de evitá-las, ganhando-se influência sobre decisões presentes" (BECK, 1999, p. 30). O agenciamento global do risco está pedindo, assim, que os professores de ciências se tornem manejadores permanentes do imprevisível quando os riscos deixam de serem futuros encenados e se tornam presentes carnais, aqueles a quem educar para viver "em um estado contínuo de excitabilidade patológica" (MASSUMI, 2015, p. 11). Este agenciamento marca tanto a virtuosidade, na expressão de Paolo Virno (2013), da educação científica quanto a atuação de professores, já que devem ocorrer nas fronteiras diluídas entre trabalho, vida e política ao se organizarem subjetivamente pela sempre incerta e imponderável avaliação dos riscos.

Como os riscos não são governáveis nem quantificáveis, mas somente encenáveis, este processo é, sobretudo, na notação de Brian Massumi (2015, p. 14), afetivo-relacional, "é a economia em seu limite comportamental absoluto de agitações tendenciais em potencial de prontidão incerta". Dito de outro modo, Massumi (2015) nota que não há simplesmente 
conhecimento prospectivo quando se trata de economia, de que é em torno tanto do instável e do incalculável quanto do hipersensível que todo o neoliberalismo gira. O risco configurase como um dispositivo afetivo de regulação da docência em ciências porque alimenta-se dessa incerteza, sobre e em torno da qual os professores devem, agora, agir e formar, no mesmo passo que também a alimenta material e subjetivamente, já que o risco confirma a interpretação fantasmática de sua causa e de sua angústia - o desenvolvimento científico e tecnológico irrefletido que, para torcer a célebre frase de Francis Fukuyama (1992), nos colocou diante do fim da história, para o qual cabe à educação científica nos salvar. Esse agenciamento global não somente aponta para como está em curso uma transição da educação científica, e até mesmo da instituição escolar, de um espaço limitado de confinamento para um processo no qual a gramática do mercado opera e os discursos neoliberais circulam.

Aquilo que o risco projeta é a incerteza como não mais extirpável da vida social, nem mesmo com mais educação ou mais conhecimento científico. Ao contrário, a atuação dos professores de ciência é aquela que torna a educação o modo de aprender a viver com a incerteza instalada no coração dos laços sociais por meio da linguagem do empresariamento e do individualismo. Mais uma vez, isso significa que os resultados serão indecidíveis para qualquer caso particular ou contexto local. Não há, no fim das contas lugar para escapar. Educar cientificamente não eliminará o risco concreto de que, sob condições complexas da incerteza, ser professor de ciências é desenvolver habilidades para atuar sobre esse desconhecido.

Poucas pesquisas estão disponíveis sobre as percepções dos alunos de risco e benefício no contexto da ciência e tecnologia. Os alunos às vezes veem os danos sociais do fracasso tecnológico como inaceitáveis. Por outro lado, alguns acreditam que se o risco é pessoal e voluntário, então faz parte da vida e não deve ser preocupação dos outros (ou da sociedade). Ajudar os alunos a desenvolver uma compreensão dos riscos e benefícios nas áreas de saúde, perigos naturais - e ciência e tecnologia em geral - representa um desafio para os professores do ensino médio. Os alunos do ensino médio geralmente estão cientes das questões ciência-tecnologia-sociedade pela mídia, mas sua consciência está repleta de malentendidos. Os professores devem começar a desenvolver a compreensão do aluno com exemplos concretos e pessoais que evitem um foco exclusivo nos problemas (ESTADOS UNIDOS, 2013, p. 167).

O trecho do documento estado-unidense é mais um dos tantos exemplos disparadores que indicam como a economização neoliberal das subjetividades docentes em ciências recai em ambivalentes e ambíguos movimentos produtivos, ao modo como Massumi (1992) sugeriu que o agenciamento é a "junção de elementos separados através do acaso de encontros persistentes, aparentemente estáveis, mais ou menos reproduzíveis, conglomerados capazes de serem tomados por sua própria ilusão objetiva de identidade" ( $\mathrm{p}$. 13). A própria facilidade com que o risco pode se espalhar e proliferar através de diferentes documentos curriculares em diferentes países torna o agenciamento global do risco um ambiente de subjetivação altamente complexo. Em resumo, a ideia mesma de uma política 
unificada de subjetivação neoliberal da docência em ciências é produzida, em certo sentido, para aparecer como um terreno totalizante, obliterando sua multiplicidade, é mais um efeito do que propriamente marca de sua constituição.

Do risco sem definição ao gestor do imprevisível, do capacitador de habilidades ao calculista da incerteza, reconhecemos, nestes textos curriculares, a multiplicidade subjetiva da racionalidade neoliberal, sua desterritorialização (DELEUZE; GUATTARI, 2004), por assim dizer, e a forma como está (des)articulando unidades. Nesse sentido, movimento ou fluxo não são necessariamente sinônimos de mudanças radicais ou de resistência, pelo menos não de forma direta. Antes, tornam necessário que professores de ciências passem a ensinar, antes que seja tarde, indivíduos a navegar por esse ambiente movente e instável do neoliberalismo, a cultivarem tendências para lidar com sua agitação e a perceber a maneira como resulta em ações que determinam a direção de suas vidas. Em outras palavras, uma rede múltipla de fluxos e movimentos que une discursos acadêmicos, afetos, textos curriculares, arenas nacionais, educação científica e projetos de formação de professores congrega, agrega e (re)constitui subjetividades docentes em ciências, chamando-as a autogerenciar o risco.

\section{Para Finalizar}

A regulação da docência em ciências pela experiência subjetiva do risco e sua complementar busca de segurança e cálculo segue a reificação dos ideais de constituição de um eu autônomo, ativo, responsável e reflexivo, no momento no qual a incerteza se instalou na vida pela corrosão tanto da relacionalidade social quando das próprias condições materiais para o estabelecimento de tais laços. Uma era, na qual, a subjetivação de professores de ciências deve ser inserida, de uma vez por todas, no "espaço aberto da mobilidade, por uma modulação da precariedade e da insegurança" (LAZZARATO, 2014, p. 15). Uma série de fluxos e movimentos estão constituindo este agenciamento global do risco, dando corpo, na educação em ciências, aquilo que Deleuze e Guattari (2004, p. 86) chamaram de micropolítica da insegurança: "a administração de uma grande segurança molar organizada tem por correlato toda uma microgestão de pequenos medos, toda uma insegurança molecular permanente, a tal ponto que a fórmula dos ministérios do interior poderia ser: uma macropolítica da sociedade para e por uma micropolítica da insegurança”. Sua multiplicidade incorpora diversos componentes discursivos e afetivos aos textos curriculares e torna-se um estímulo para considerar o potencial da teorização curricular em problematizar e interrogar os agenciamentos globais, se materializando através desses textos bem como sendo articulados através de seus diagramas de forças.

Nós gostamos, deste modo, de pensar a teorização curricular como um apelo, uma espécie de exercício com um ímpeto ético e político, exigindo o quão é produtiva para investigar a subjetivação docente; o que nós estamos nos tornando como professores no ensino de ciências quando o risco é assumido como um princípio articulador, e, por isso mesmo, múltiplo e aberto, dos currículos de educação científica. No entanto, seguir neste 
sentido implica um certo deslocamento da "ação política" e, talvez de forma mais importante, do "neoliberalismo". Escrever em termos de agenciamento global do risco foi também nosso exercício, mesmo que tentativo e tateante, de confrontar até que ponto a política de racionalidade neoliberal está embutida, assim, em nossa própria imaginação teórica. Nós buscamos mostrar como o agenciamento global do risco está estabelecendo condições de subjetivação através da reunião de diferentes elementos e unidades, ao mesmo tempo desmontando e remontando a subjetividade docente em ciências. As transformações que professores de ciências devem empreender como e sobre os riscos estão longe de serem, assim, atos radicais. Por outra via, essas transformações são discretamente conservadoras, tentando manter a segurança ou qualquer coisa semelhante na era da incerteza. Frequentemente, para tanto, esses textos sonham com transformações neoliberais da educação em ciências no sentido de que cabe aos professores desenvolver as estruturas cognitivas de empresariamento, responsabilidade, escolha e decisão individual.

Queremos, aqui, sublinhar o papel absolutamente central de uma violência imaginativa nos termos pelos quais pensamos sobre "sociedade", "mercado" e "economia" e, na verdade, muitas ideias sobre liberdade, risco e responsabilidade. Para dar sentido ao nonsense da cultura do gerencialismo e da performatividade em nós, teríamos que considerar a possibilidade de que se trata, sobretudo, de solapar e prevenir a emergência da alteridade, alçando-a ao campo do impossível ou do irrealizável. É somente ao se articular com outros discursos que temem para onde a diferença radical pode nos levar que a sensação de sucesso implacável da racionalidade neoliberal é garantida e dispersada. É, portanto, sua eficiência homogênea, a capacidade como sistema de ser a mesma coisa, de fazer a mesma coisa a cada vez ou ter o mesmo efeito independentemente de suas combinações que estão em questão. Nosso desafio foi, deste modo, realizar uma analítica de como agenciamento global do risco está regulando a docência em ciências sem lhe atribuir uma lógica interna ou coerência "de forma a evitar a reprodução da sua inelutabilidade" (MITCHELL, 2002, p. 14) para que processos culturais, dinâmicas sociais e fatos políticos não sejam subsumidos a mesma história universalizável da economização da vida; uma história na qual não apenas os fatores "são descritos de forma negativa" (MITCHELL, 2002, p. 246), quanto através da qual sua essência seria finalmente revelada.

Não obstante, o agenciamento global do risco levanta o problema da possibilidade de ação política quando as respostas táticas e exigências imediatas da educação em ciências são focadas na prática e na atuação cotidiana e localizada de professores. Um foco que acelera os movimentos de recombinação de conceitos da produção acadêmica em ensino de ciências, políticas estatais, instituições, identificações morais e tradições do discurso educacional em e entre arranjos da "nova razão do mudo" (DARDOT; LAVAL, 2013). Por isso, queremos concluir sugerindo que mobilidade e multiplicidade, por necessidade, não são politicamente disruptivas, nem complexidade e localidade constitutivamente transformadoras. $\mathrm{O}$ risco pode muito bem não ser prova de nenhuma mudança radical, quiçá fazer emergir um momento de possibilidade ético-política na educação. Ao invés disso, o risco pode ser uma dissolução ameaçadora, o buraco negro de Deleuze (DELEUZE; PARNET, 1998), que caberia a docência em ciências incorporar. Este deslocamento exige formas de análise que possam 
explorar as ambiguidades e os paradoxos que produzem a subjetividade docente em ciências nesses movimentos de ser lançada ao desconhecido e instável do neoliberalismo.

\section{Notas:}

1. Todas as citações de textos em língua inglesa e espanhol são de tradução própria dos autores.

2. Neste ponto, seria necessário assumir que os documentos selecionados para cartografar esse agenciamento global foram também selecionados por estarem disponibilizados para acesso online e em idiomas dominados pelos autores deste texto, a saber em inglês, português ou espanhol.

3. O livro foi publicado em alemão em 1986. Sua a primeira edição da tradução para o português é de 2010.

4. Extrapola em muito o escopo deste artigo explorar a relação entre a guerra e o capitalismo, mas uma exploração densa neste sentido pode ser encontrada em Eric Alliez e Mauricio Lazzarato (2021).

5. Certamente, o uso do termo terrorismo valeria uma problematização ou suspeita quanto à sua obviedade e, neste sentido, o clássico trabalho de Talal Asad (2007) é crucial. Logo, em sua introdução o autor afirma que o terrorismo é "parte integrante das subjetividades liberais (o desejo de derrotar o terror político, o medo da vulnerabilidade social, o horror e fascínio com morte e destruição), embora o próprio terror seja colocado como sendo essencialmente parte de uma cultura não-moderna e não-liberal" (p. 2-3).

6. Os trabalhos de Márcia Serra Ferreira sobre a história da disciplina escolar Ciências no Brasil são elucidativos neste sentido. Ver, por exemplo, Ferreira (2015).

\section{Agradecimentos}

Este trabalho foi financiado pela Fundação Carlos Chagas Filho de Amparo à Pesquisa do Estado do Rio de Janeiro (FAPERJ) por meio do processo E-26/201.863/2020.

\section{Referências}

ÁFRICA DO SUL. Department of Basic Education. National Curriculum Statement. 2011. Acesso em: 25 jan. 2021. Disponível em: https://www.education.gov.za/Curriculum/.

ALLIEZ, Eric; LAZZARATO, Mauricio. Guerras e capital. São Paulo: Ubu Editora, 2021.

AMOBRÓZIO, Aldo. Empresariamento da vida: a função do discurso gerencialista nos processos de subjetivação inerentes a governamentalidade neoliberal. Curitiba: Appris, 2018.

ASAD, Talal. On suicide bombing. Nova York, US: Columbia University Press, 2007.

AUSTRÁLIA. Australian Curriculum, Assessment and Reporting Authority. The Australian curriculum Science. 2015. Acesso em: 23 jul. 2021. Disponível em: https://www.australiancurriculum.edu.au/Home

BALDAN, Merilin; CUNHA, Érika. Povoando subjetividades na "nova" política para a formação de professores no Brasil: uma discussão acerca das competências. Série-Estudos, v. 25, n. 55, p. 51-71, set./dez. 2020. Acesso em: 15 jul. 2021. Disponível em: https://doi.org/10.20435/serie-estudos.v0i0.1501

BALL, Stephen J. Reformar escolas/reformar professores e o terror da performatividade. Revista Portuguesa de Educação, v. 15, n. 2, p. 3-23, 2002. Acesso em: 15 ago. 2021. Disponível em: https://www.redalyc.org/articulo.oa?id=37415201 
BALL, Stephen John. Education Reform: a critical and post-structural approach. Open University Press, 1994.

BALL, Stephen John. Educação Global S.A: novas redes políticas e o imaginário neoliberal. Ponta Grossa: UEPG, 2014.

BECK, Ulrich. Sociedade de risco: rumo a uma outra modernidade. 2. ed. São Paulo, BR: Editora $34,2013$.

BECK, Ulrich. World Risk Society. Cambridge, UK: Polity Press, 1999.

BERLANT, Lauren. Cruel Optimism. Durham: Duke University Press, 2011.

BIESTA, Gert. The Beautiful Risk of Education. London, UK: Routledge, 2016.

BRASIL. Ministério da Educação. Base Nacional Comum Curricular. Brasília, DF. 2018. Acesso em 20 julho 2021. Disponível em: http://basenacionalcomum.mec.gov.br/a-base.

BROWN, Wendy. Undoing the Demos: neoliberalism's stealth revolution. Nova York, US: The MIT Press, Zone Books, 2015.

BROWN, Wendy. Nas ruínas do neoliberalismo: a ascensão da política antidemocrática no ocidente. São Paulo: Editora Filosófica Politeia, 2019.

CASTEL, Robert. From dangerousness to risk. In: BURCHELL, Graham; GORDON, Colin; MILLER, Peter. The Foucault effect: studies in governmentality: Chicago, US: University of Chicago, 1991. p. 281-98.

CAMPBELL, Elaine. A vida emocional do poder governamental. Ecopolítica, n. 1, p. 43-76, 2011.

CHAGAS, Guilherme; LOCKMANN, Kamila. Alargamento das Funções da Escola: as brumas do neoliberalismo. Cadernos de Pesquisa: Pensamento Educacional, v. 16, p. 35-54, 2021. Acesso em: 18 ago. 2021. Disponível em: https://doi.org/10.35168/2175-2613.UTP.pens_ed.2021.Vol16.N42.pp35-54

CHILE. Ministerio de Educación de Chile. Unidad de Currículum y Evaluación: bases curriculares. 2019. Acesso em” 15 jul 2021. Disponível em: https://www.curriculumnacional.cl/portal/.

CHRISTENSEN, Clare. Risk and school science education. Studies in Science Education, v. 4, n.2, p. 205223, 2009. Acesso em: 11 ago. 2021. Disponível em: https://doi.org/10.1080/03057260903142293

COLLIER, Stephen; ONG, Aihwa. Global Assemblages, Anthropological Problems. In: COLLIER, Stephen; ONG, Aihwa (Orgs.). Global assemblages: technology, politics and ethics as anthropological problems. Malden, US: Blackwell, 2005.

COMISSÃO EUROPEIA. Report to the European Commission. Science Education for Responsible Citizenship. 2015. Acesso em: 25 abr. 2021. Disponível em: http://ec.europa.eu/research/swafs/pdf/pub_science_education/KI-NA-26-893-EN-N.pdf

DARDOT, Pierre; LAVAL, Christian. A nova razão do mundo. São Paulo: Boitempo Editorial, 2013.

DELANDA, Manuel. A new philosophy of society. Londres, UK: Continuum, 2006

DELEUZE, Gilles; GUATTARI, Félix. Mil platôs: capitalismo e esquizofrenia. São Paulo: Ed. 34, 2004. v. 3.

DELEUZE, Gilles; GUATTARI, Félix. Mil platôs: capitalismo e esquizofrenia. São Paulo: Ed. 34, 2012. v. 5.

DELEUZE, Gilles; GUATTARI, Félix. Mil platôs: capitalismo e esquizofrenia. São Paulo: Ed. 34, 2017. v. 1.

DELEUZE, Gilles; PARNET, Claire. Diálogos. São Paulo: Escuta, 1998.

DELEUZE, Gilles. Post Scriptum sobre as Sociedades de Controle. In DELEUZE, Gilles. Conversações 1972-1990. Rio de Janeiro: Editora 34, 1992.

DELEUZE, Gilles. O método da dramatização. In: LAPOUJADE, David. (Org.). A ilha deserta e outros textos. São Paulo: Iluminuras, 2004. p. 131-162.

DELEUZE, Gilles. Foucault. São Paulo: Brasiliense, 2005.

DOUGLAS, Mary. Risk and Blame: essays in cultural theory. London, UK: Routledge. 1994.

EDWARDS, Richard. Flexibility, reflexivity and reflection in the contemporary workplace. International Journal of Lifelong Education, v. 17, n. 6, p. 377-388, 1988. Acesso em: 12 ago. 2021. Disponível em: 
https://doi.org/10.1080/0260137980170604

EHRENBERG, Alain. $\mathbf{O}$ culto da performance: da aventura empreendedora à depressão nervosa. Aparecida: Ideias \& Letras. 2010.

ESPANHA. Ministerio de Educación, Cultura y Deporte. Real Decreto 1105/2014 y Real Decreto 126/2014. 2014. Acesso em 20 abr. 2021. Disponível em: https://www.educacionyfp.gob.es/educacion/mc/lomce/curriculo.html

ESTADOS UNIDOS. National Research Council. Next Generation Science Standards. 2013. Acesso em 18 abr. 2021. Disponível em: https://www.nextgenscience.org

EWALD, François. Insurance and risk. In: BURCHELL, Graham; GORDON, Colin; MILLER, Peter. The Foucault effect: studies in governmentality: Chicago, US: University of Chicago; 1991. p. 197-210.

FERREIRA, Márcia Serra. História do Currículo e das Disciplinas: produzindo uma abordagem discursiva para investigar a formação inicial de professores nas Ciências Biológicas. In: LEITE, Miriam Soares; GABRIEL, Carmen Teresa. (Org.). Linguagem, Discurso, Pesquisa e Educação. Rio de Janeiro: DePetrus/FAPERJ, 2015. p. 265-284.

FISCHER, Rosa Maria Bueno. Foucault e a análise do discurso em educação. Cadernos de Pesquisa, n. 114, p. 197-223, nov. 2001. Acesso em: 15 ago. 2021. Disponível em: https://doi.org/10.1590/S010015742001000300009

FOUCAULT, Michel. História da sexualidade I: a vontade de saber. Rio de Janeiro: Graal, 1999.

FOUCAULT, Michel. Segurança, território, população: curso dado no Collège de France (1977-1978). São Paulo: Martins Fontes, 2008.

FOUCAULT, Michel. Nascimento da Biopolítica: curso no Collège de France (1978-1979). Trad. Eduardo Brandão. Martins Fontes, São Paulo, 2010.

FOUCAULT, Michel. A ordem do discurso - Aula inaugural no Collège de France, pronunciada em 2 de dezembro de 1970. 24. ed. São Paulo: Edições Loyola, 2012.

FUKUYAMA, Francis. O fim da história e o último homem. São Paulo: Rocco, 1992.

GARRICK, John; USHER, Robin. Flexible learning, contemporary work and enterprising selves. Electronic Journal of Sociology, v. 5, n. 1, 2000. Acesso em: 12 abr. 2021. Disponível em: http://www.sociology.org/content/vol005.001/garrick-usher.html

GROSSBERG, Lawrence. Under the cover of chaos: Trump and the Battle for the American Right. Londres: Pluto Press, 2018.

GUIVANT, Julia. A Trajetória das Análises de Risco: Da Periferia ao Centro da Teoria Social. BIB, n. 46, v. 2., p. 3-38, 1998.

ILLOUZ, Eva. Amor nos tempos do capitalismo. Rio de Janeiro: Jorge Zahar, 2001.

INGLATERRA. Department For Education. The National Curriculum in England. 2014. Acesso em 15 abr. 2021. Disponível em: https://assets.publishing.service.gov.uk/government.

JENKINS, Edgar. 'Science for all': Time for a paradigm shift? In Robin Millar \& Jonathan Osborne (Orgs.), Improving science education: the contribution of research. 2000. p. 207-226. Buckingham, UK: Open University Press.

KOLSTØ, Stein Dankert. Patterns in Students' Argumentation Confronted with a Risk-focused Socio-scientific Issue. International Journal of Science Education, v. 28, n. 14, p. 1689-1716, 2006. Acesso em: 15 abr. 2021. Disponível em: https://doi.org/10.1080/09500690600560878

LAZZARATO, Maurizio. O governo das desigualdades: crítica da insegurança neoliberal. São Carlos: Editora UFSCar, 2011.

LAZZARATO, Maurizio. Signos, máquinas, subjetividades. São Paulo: Edições Sesc, 2014.

LEVINSON, Ralph, KENT, Phillip, PRATT, David, KAPADIA, Ramesh, YOGUI, Cristina. Developing a 
pedagogy of risk in socio-scientific issues. Journal of Biological Education, v. 45, n. 3, 136-142, 2011. Acesso em: 29 abr. 2021. Disponível em: https://doi.org/10.1080/00219266.2011.576260

LOCKMANN, Kamila; MACHADO, Roseli. Pátria educadora? Uma análise das propostas para o ensino público brasileiro. Pro-posições. v. 29, n. 1, p. 128-152, jan./abr. 2018. Acesso em: 29 ago. 2021. Disponível em: https://doi.org/10.1590/1980-6248-2016-0020

LOREY, Isabell. State of Insecurity. London, UK: Verso, 2014.

MACEDO, Elizabeth. Base nacional curricular comum: a falsa oposição entre conhecimento para fazer algo e conhecimento em si. Educação em Revista, v. 32, p. 45-68, 2016. Acesso em: 22 ago. 2021. Disponível em: https://doi.org/10.1590/0102-4698153052

MACEDO, Elizabeth. Por uma leitura topológica das políticas curriculares. Archivos Analíticos de Políticas Educativas/Education Policy Analysis Archives, v. 24, p. 26, 2016. Acesso em: 15 jul 2021. Disponível em: http://dx.doi.org/10.14507/epaa.v24.2075

MACEDO, Elizabeth. As demandas conservadoras do Movimento Escola Sem Partido e a Base Nacional Curricular Comum. Educação \& Sociedade, v. 38, p. 507-524, 2017. Acesso em: 22 set. 2021. Disponível em: https://doi.org/10.1590/ES0101-73302017177445

MACEDO, Elizabeth; RANNIERY, Thiago. Políticas públicas de currículo: diferença e a ideia de público. Currículo sem fronteiras, v. 18, p. 739-759, 2018. Acesso em: 18 ago. 2021. Disponível em: http://www.curriculosemfronteiras.org/vol18iss3articles/macedo-ranniery.pdf

MASSUMI, Brian. A User's Guide to Capitalism and Schizophrenia: Deviations from Deleuze and Guattari. Cambridge: The MIT Press, 1992.

MASSUMI, Brian. The Power at the End of the Economy. Durham: Duke University Press, 2015.

MILLAR, Robin. Twenty First Century Science: Insights from the Design and Implementation of a Scientific Literacy Approach in School Science. International Journal of Science Education, v. 28, n. 13, p. 14991521, 2006. Acesso em 07 set. 2021. Disponível em: https://doi.org/10.1080/09500690600718344

MITCHELL, Timothy. Rule of Experts: Egypt, Techno-Politics, Modernity. Berkeley, US: University of California Press, 2002.

MOÇAMBIQUE. Ministério da Educação e Desenvolvimento Humano. Plano Curricular do Ensino Básico. 2020. Acesso em 13 abr. 2021. Disponível em: http://www.mined.gov.mz/DN/DINEP/Documents/PCEB.pdf

NOVA ZELÂNDIA. Ministry of Education. The New Zealand Curriculum. 2007. Acesso em 13 jun. 2021. Disponível em: https://nzcurriculum.tki.org.nz/The-New-Zealand-Curriculum

OKSALA, Johanna. Como ler Foucault. Rio de Janeiro: Zahar, 2011.

ONTÁRIO, Canadá. Ministry of Education. The Ontario Curriculum. 2008. Acesso em 25 jun. 2021. Disponível em: http://www.edu.gov.on.ca/eng/curriculum/secondary/

PÁLSSON, Gísli; RABINOW, Paul. The Iceland Controversies: Reflections on the Transnational Market of Civic Virtue. In: COLLIER, Stephen; ONG, Aihwa (Orgs.). Global assemblages: technology, politics and ethics as anthropological problems. Malden, US: Blackwell, 2005. p. 91-104.

PIMENTEL-JÚNIOR, Clívio; DIAS, Rosanne Evangelista; CARVALHO, Maria Inez. Significações de qualidade e crise da educação científica nas políticas curriculares para o ensino de ciências. Investigações em Ensino de Ciências, v. 24, p. 147-168, 2019. Acesso em 02 set. 2021. Disponível em: http://dx.doi.org/10.22600/1518-8795.ienci2019v24n3p147

PIMENTEL-JÚNIOR, Clívio. Articulações discursivas em torno do significante natureza da ciência: currículo, formação, política. Teias, v. 18, p. 88-104, 2017. Acesso em 12 set. 2021. Disponível em: https://doi.org/10.12957/teias.2017.26713

POPKEWITZ, Thomas; BRENNAN, Marie. (Eds). Foucault's Challenge: discourse, knowledge and power in 
education. New York: Teachers College Press, 1998.

PORTOCARRERO, Vera. As ciências da vida: de Canguilhem a Foucault. Rio de Janeiro: Editora Fiocruz, 2009.

PORTUGAL. Ministério da Educação. Orientações Curriculares e Aprendizagens Essenciais. 2004. Acesso em 25 jun. 2021. Disponível em: https://www.dge.mec.pt/ensino-basico.

REINO UNIDO. GCSE - England, Wales, and Northern Ireland. Twenty First Century Science. 2011. Acesso em 10 jan. 2021. Disponível em: https://www.ocr.org.uk/gcsec21combinedscience.

ROLNIK, Suely. Esferas da insurreição: notas para uma vida não cafetinada. São Paulo: n-1 edições, 2018.

ROSE, Nikolas. Governing 'Advanced' Liberal Democracies. In: ROSE, Nikolas; BARRY, Andrew; OSBORNE, Thomas. (Orgs). Foucault and Political Reason: Liberalism, Neo-liberalism, and Rationalities of Government. Londres: UCL Press, 1996. p. 37-64.

SAFLATE, Vladimir. A economia é a continuação da psicologia por outros meios: sofrimento psíquico e neoliberalismo como economia moral. In: SAFLATE, Vladimir; SILVA JÚNIOR, Nelson; DUNKER, Christian. Neoliberalismo como gestão do sofrimento psíquico. Belo Horizonte: Autêntica, 2020. p. 1746.

SCHENK, Linda, HAMZA, Karim. M., ENGHAG, Margareta, LUNDEGÅRD, Iann, ARVANITIS, Leena, HAGLUND, Karin, WOJCIK, Andrzej. Teaching and discussing about risk: seven elements of potential significance for science education. International Journal of Science Education, v. 41, n. 9, p. 1271-1286, 2019. Acesso em 16 set. 2021. Disponível em: https://doi.org/10.1080/09500693.2019.1606961

SEDDON, Terri. Capacity building: beyond state and market. Pedagogy, Culture \& Society, v. 7, p. 1, p. 3553, 1999. Acesso em 16 ago. 2021. Disponível em: https://doi.org/10.1080/14681369900200054

SEVERIANO, Pablo. Pesquisar com Michel Foucault. Textura, v. 18, n. 36, p. 265-285, jan./abr. 2016. Acesso em 19 ago. 2021. Disponível em: http://posgrad.ulbra.br/periodicos/index.php/txra/article/view/1613/1464

VIRNO, Paolo. Gramática da multidão: para uma análise das formas de vida contemporâneas. São Paulo: Annablume, 2013.

YOUDELL, Deborah. Assemblage theory and education policy sociology. In: GULSON, Kalervo N.; CLARKE, Matthew; PETERSEN, Eva Bendix. Education Policy and Contemporary Theory: implications for research. London, UK: Routledge, 2015. p. 110-121.

\section{Correspondência}

Samuel Molina Schnorr: Biólogo Licenciado e Mestre em Educação ambos pela Universidade Federal de Pelotas (UFPel). Doutor em Educação, na área de Ensino de Ciências, pela Universidade de São Paulo (USP), investigando os discursos científicos e pedagógicos (financiado pela FAPESP). Atualmente, é pesquisador de pós-doutorado na Universidade Federal do Rio de Janeiro (UFRJ), financiado pela FAPERJ (Programa Nota 10).

E-mail: schnorr.sm@gmail.com

Orcid: https://orcid.org/0000-0001-9326-1477

Thiago Ranniery: Professor Adjunto da Universidade Federal do Rio de Janeiro, na qual estou como ViceDiretor da Faculdade de Educação (2020 a 2024) e atuo como Professor Permanente do Programa de Pós-graduação em Educação na Linha Currículo, Ensino e Diferença. Licenciado em Ciências 
Biológicas pela Universidade Federal de Sergipe com Mestrado em Educação pela Universidade Federal de Minas Gerais e Doutorado em Educação pela Universidade do Estado do Rio de Janeiro.

E-mail: t.ranniery@gmail.com

Orcid: https://orcid.org/0000-0003-4399-2663

Texto publicado em Currículo sem Fronteiras com autorização dos autores. 